\title{
Modulation of Neonatal Myelopoiesis in Newborn Rats after 7 Days' Administration of Either Granulocyte-Monocyte Colony Stimulating Factor or Interleukin-3
}

\author{
MITCHELL S. CAIRO, DEBBIE MAUSS, J. MICHAEL PLUNKETT, STEVEN GILLIS, AND \\ CARMELLA VAN DE VEN \\ Division of Hematology-Oncology, Childrens Hospital of Orange County, University of California, Irvine, \\ Orange, California 92668 and Immunex, Seattle, Washington 98105
}

\begin{abstract}
Single-pulse administration of either recombinant human granulocyte-monocyte colony stimulating factor or recombinant human granulocyte colony stimulating factor to newborn rats has previously been demonstrated to increase the peripheral neutrophil count and modulate bone marrow (BM) neutrophil pools. In our present study, we investigated the effects of $7 \mathrm{~d}$ of either recombinant murine granulocyte-monocyte colony stimulating factor (rmGM-CSF) $(75 \mu \mathrm{g} / \mathrm{kg} / \mathrm{d})$ or recombinant murine IL-3 (rm IL-3) $(10 \mu \mathrm{g} / \mathrm{kg} / \mathrm{d})$ on newborn rat myelopoiesis. Sprague Dawley newborn rats $(\geq 24 \mathrm{~h})$ were injected (intraperitoneally) daily for $7 \mathrm{~d}$ with either rmGMCSF, rmIL-3, or PBS/BSA. rmGM-CSF induced a significant increase in the peripheral neutrophil count on d 3 ( $p$ $<0.03)$ and $\mathrm{d} 7(p<0.001)(75 \%$ increase). Additionally, rmGM-CSF induced a $50 \%$ increase in the BM neutrophil storage pool $(p<0.025)$. rmIL-3 increased the BM colony forming unit-granulocyte monocyte pool $(p<0.001)$; however, it failed to increase the peripheral neutrophil count or BM neutrophil storage pool. Neither CSF increased the BM neutrophil proliferative pool or BM colony forming unit-granulocyte monocyte proliferative rate. Additionally, $7 \mathrm{~d}$ of rmGM-CSF with or without antibiotics did not synergistically alter the mortality rate after group B streptococcol inoculation. This study suggests that rmIL-3 appears to stimulate more neonatal myeloid committed progenitor cell activity compared with rmGM-CSF. Optimal modulation of neonatal myelopoiesis may require the use of a sequential combination of hematopoietic CSF, namely an early-acting CSF followed by a more lineage myeloidspecific CSF. (Pediatr Res 29: 504-509, 1991)
\end{abstract}

\section{Abbreviations}

CSF, colony stimulating factor

G-CSF, granulocyte colony stimulating factor

GM-CSF, granulocyte-monocyte colony stimulating factor NSP, neutrophil storage pool

NPP, neutrophil proliferative pool

CFU-GM, colony forming unit-granulocyte monocyte GBS, group B streptococcus rh, recombinant human

Received April 23, 1990; December 6, 1990

Correspondence and reprint requests: Mitchell S. Cairo, M.D., Director, Hematology/Oncology Research and Bone Marrow Transplantation, Children's Hospital of Orange County, 455 S. Main Street, Orange, CA 92668.

Supported by grants from the Pediatric Cancer Research Foundation and the Walden W. and Jean Young Shaw Foundation. CA.

Presented in part at the Society of Pediatric Research, May 1990, Anaheim, rm, recombinant murine

i.p., intraperitoneal(ly)

Neonatal host defense is characterized by a significant developmental immaturity in various components of the immune system, predisposing the neonate to a high mortality rate during overwhelming bacterial infection (1). Significant reductions in myeloid progenitor proliferation and bone marrow NSP, and, additionally, a tendency to develop peripheral neutropenia, characterize some of the most important deficiencies in neonatal host defense (2-4). During experimental sepsis, newborn rats also demonstrate markedly different myeloproliferative responses compared with their adult counterparts (5). Newborn rats, inoculated with bacterial organisms such as GBS fail to increase their already high myeloid progenitor proliferative rate, decrease their myeloid bone marrow committed stem cell pool (CFU-GM), and, most importantly, deplete their already reduced NSP (polymorphonuclear leukocyte + band + metamyelocyte) (5).

Bone marrow myeloid proliferation and egress of mature effector neutrophils are influenced in part by the proliferative and differentiating effects of hematopoietic CSF (6-9). Some CSF induce proliferation of stem cells, whereas others affect more lineage-specific, later-acting, committed progenitor cells and the functional activation of mature effector cells. Class 1 factors such as GM-CSF and IL-3 appear to act on earlier and more pluripotent stem cell progenitors compared with class 2 factors such as G-CSF, which have been demonstrated to act on more lineage-specific, committed myeloid progenitor cells (6-9). CSF appears, in fact, to be the major regulator of increased peripheral myeloid cell production during states of sepsis or increased demand (6).

IL-3 was first isolated from the Gibbon cell line MLA-144 and has recently been demonstrated to be present in the growth factor-rich chromosome $5 \mathrm{q}$ region (10-13). Human IL-3 has a limited homology at the amino acid level with murine IL-3 (29\%) (6). IL-3 appears to stimulate the growth and proliferation of very early pluripotent bone marrow progenitor cells and, in adult studies of hematopoiesis, has been demonstrated to stimulate the clonal proliferation of erythroid, myeloid, and megakaryocytic bone marrow progenitor cells $(14,15)$. IL-3 appears to preferentially induce the stimulation of early progenitor cells. Effects of IL-3 on later, more lineage specific, committed progenitor cells may be secondary to the effects of class 2 CSF such as G-CSF, monocyte-CSF, and erythropoietin.

GM-CSF, another lymphokine, was first purified to homogeneity from the Mo T lymphoblastoid cell line (16). Human GM- 
CSF is also a small glycoprotein (22000 D) and, despite sharing a $60 \%$ amino acid homology with murine GM-CSF, appears to have diminished myeloproliferative effects when used in experiments with murine animals (8). GM-CSF also seems to modulate proliferation of bone marrow progenitor cells, but has been demonstrated to influence the growth of only CFU-GM and CFU-eosinophil, resulting in an increase in peripheral granulocytes, monocytes, and eosinophils (17). GM-CSF, however, besides having the ability to induce proliferation of committed progenitor cells, has also been demonstrated to enhance mature effector neutrophil function of both neonatal and adult mature neutrophils (18).

We have previously demonstrated that single-pulse administration of G-CSF or GM-CSF to newborn rats results in a significant increase in peripheral neutrophilia (19). Additionally, we have demonstrated that single-pulse rhG-CSF given prophylactically or simultaneously with antibiotics during experimental GBS infection (in newborn rats) reduces the mortality rate compared with antibiotic therapy alone (20). Recently, we have demonstrated that prolonged prophylactic administration (7 d) of a more lineage-specific CSF such as rhG-CSF to newborn rats significantly modulates myelopoiesis and the response to GBS sepsis (21). In our present study, we have investigated and compared the effects of $7 \mathrm{~d}$ of administration of both class 1 factors, rmGM-CSF and rmIL-3, and their modulation of myelopoiesis in the newborn rat.

\section{MATERIALS AND METHODS}

Murine GM-CSF. rmGM-CSF (Immunex Corporation, Seattle, WA) is expressed in yeast, and purified to homogeneity before formulation in RPMI. SDS-PAGE was used to confirm the purity of the product by the presence of a single protein band. Biologic activity of $4 \times 10^{7} \mathrm{U} / \mathrm{mg}$ was determined by granulocyte macrophage colony formation (CFU-GM) of nonadherent mouse bone marrow cells in semisolid media. The Limulus amebocyte lysate assay was used to demonstrate the absence of measurable endotoxin. Purified rmGM-CSF was used

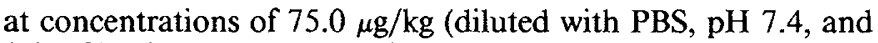
$0.025 \%$ BSA; Sigma Chemical Co., St. Louis, MO). A doseresponse study of $1-75 \mu \mathrm{g} / \mathrm{kg} / \mathrm{d}$ demonstrated maximal neutrophil counts with $75 \mu \mathrm{g} / \mathrm{kg} / \mathrm{d}$.

Murine IL-3. Mouse recombinant IL-3 (Genzyme, Cambridge, $\mathrm{MA}$ ), is expressed in COS cells and purified to homogeneity before formulation in PBS/0.1\% BSA. SDS-PAGE was used to confirm the purity of the product by the presence of a single protein band. The biologic activity was determined to be $1 \times 10^{6}$ $\mathrm{U} / \mathrm{mg}$, and the Limulus amebocyte lysate assay was used to demonstrate the absence of measurable endotoxin. rmIL-3 was used at concentrations of $10 \mu \mathrm{g} / \mathrm{kg}$ (diluted with PBS and $0.025 \%$ BSA). A dose-response study of $0.1-10.0 \mu \mathrm{g} / \mathrm{kg} / \mathrm{d}$ demonstrated maximal neutrophil counts with $10 \mu \mathrm{g} / \mathrm{kg} / \mathrm{d}$.

$G B S$. GBS, type III, Norris, was kindly provided by Dr. Gerald Fisher (Uniformed Services Hospital, Bethesda, MD). The organism was isolated from an infected neonate and serotyped by the precipitin method using rabbit antisera. The organism was grown in Todd-Hewitt broth to logarithmic phase and then aliquoted and stored at $-70^{\circ} \mathrm{C}$ until use. Aliquots were thawed and allowed to grow to maximum phase growth in fresh Todd-Hewitt broth. Organisms were then sedimented by centrifugation and washed three times in sterile PBS. Concentration of bacteria was standardized by its $O D$ at $620 \mathrm{~nm}$, and a suspension of $3 \times 10^{6}$ organisms/g body wt $/ 0.100 \mathrm{~mL}$ was prepared for injection.

Animal inoculation. Litters of albino Sprague Dawley neonatal rats (Bantin-Kingman Laboratories, Fremont, CA) $\leq 24 \mathrm{~h}$ old $(6-8 \mathrm{~g})$ were used during this study. Mothers of the litters were received $1 \mathrm{wk}$ before delivery and were housed at the vivarium at the University of California Irvine Medical Center. They were maintained at constant room temperature, with water and rodent feed (Purina Chow, Ralston-Purina Co., St. Louis, MO) ad libitum. Approval for this study was granted by the Animal Use Committee at the university. Before inoculation of the neonatal rat, the site of injection was washed with Betadine solution (povidone-iodine, 10\%; Purdue Frederick, Norwalk, CT). Daily (7 d) i.p. injections of rmGM-CSF or rmIL-3 were accomplished with a sterile tuberculin syringe fitted with a 27.5-gauge needle. GBS was injected s.c. at the tail region of the animal with a sterile tuberculin syringe; antibiotics were administered intramuscularly at the hind leg.

Quantification of circulating, proliferative, and storage pools. Blood samples were obtained daily by nicking the jugular vein with a sterile needle and collecting $10 \mu \mathrm{L}$ of free-flowing blood. Samples were electronically counted (Serano-Baker Diagnostics, Allentown, PA); blood smears were prepared and stained with Wright stain, and a 100-200 cell differential was performed. Absolute neutrophil counts were determined by the multiplication of the nucleated cell count by the percentage of neutrophils in the differentials. Bone marrow NSP (polymorphonuclear leukocyte + band + metamyelocyte) and NPP (blasts + promyelocyte + myelocyte) were determined on $\mathrm{d} 8$ by the method of Christensen et al. (5). Briefly, neonatal femurs were aseptically removed, and the contents flushed into a known quantity of Hanks' balanced salt solution (Gibco Laboratories, Grand Island, NY). Livers and spleens were also removed on d 8 in a similar manner, and finely minced in a known quantity of Hanks' balanced salt solution. Electronic cell counts were performed on the bone marrow, and a 500-cell differential count was obtained on Wright-stained cytospin preparations.

CFU-GM proliferative rate. Proliferative rates of CFU-GM were evaluated by the thymidine suicide method of Christensen et al. (5). Bone marrow and liver and spleen cells from neonatal rats were placed into each of two $50-\mathrm{mL}$ centrifuge tubes. To the first aliquot was added $0.34 \mu \mathrm{g}$ nonradioactive thymidine in a volume of $0.1 \mathrm{~mL}$. The other aliquot received $0.34 \mu \mathrm{g}$ methyl${ }^{3} \mathrm{H}$-thymidine containing $0.1 \mathrm{mCi}$ (sp act, $75 \mathrm{Ci} / \mathrm{mmol}$; ICN Radiochemicals, Irvine, CA). The tubes were incubated for 20 min at $37^{\circ} \mathrm{C}$ while agitating every $5 \mathrm{~min}$. Thymidine uptake was halted by adding $30 \mathrm{~mL}$ of ice cold $\alpha$-minimum essential medium with $5 \% \mathrm{FCS}$ and $100 \mu \mathrm{g} / \mathrm{mL}$ nonradioactive thymidine. The cell suspensions were then centrifuged and washed twice with the $\alpha$-minimum essential medium FCS/thymidine media. Cells were then added in the same $1.1 \%$ methylcellulose $/ \alpha$-media described above. Colonies were allowed to develop for $14 \mathrm{~d}$ in a $5 \% \mathrm{CO}_{2}$ incubator at $37^{\circ} \mathrm{C}$, and thymidine suicide rate was determined by subtracting the average number of colonies formed per plate by cells exposed to $\left[{ }^{3} \mathrm{H}\right]$ thymidine from the average number of colonies per plate formed by cells exposed to nonradioactive thymidine, and dividing by the average colonies per plate from cells exposed to nonradioactive thymidine.

$C F U-G M$ colony quantification. Bone marrow and liver/spleen cells were collected as described above. Cells were then suspended in $\alpha$-media (Gibco Laboratories) with $1.1 \%$ methylcellulose (Terry Fox Laboratories, Vancouver, BC), 30\% vol/vol FCS (Hyclone Laboratories, Logan, UT), 10\% BSA (Sigma Chemical Co.), $14.3 \times 10^{-3} \mathrm{M}$ mercaptoethanol, $0.01 \%$ vol/vol murine spleen cell conditioned medium (PWM-SCCM; Terry Fox Laboratories), and $1 \mathrm{U} / \mathrm{mL}$ erythropoietin (Amgen, Thousand Oaks, CA). Penicillin (100 $000 \mathrm{U} / \mathrm{L})$ and streptomycin $(100 \mathrm{mg} / \mathrm{L})$ were also added. Cell suspensions were plated in triplicate in 10 $\times 35 \mathrm{~mm}$ tissue culture dishes (Nunc, Copenhagen, Denmark) and incubated at $5 \% \mathrm{CO}_{2}, 37^{\circ} \mathrm{C}$, in a high humidity atmosphere. Cultures were evaluated at $14 \mathrm{~d}$ with aggregates of $>50$ cells considered "colonies." Colonies were plucked at random, placed on a slide and stained, and lineage specificity was confirmed.

Treatments. To determine rmGM-CSF effect on the modulation of sepsis, newborn litters were given rmGM-CSF i.p. (75.0 $\mu \mathrm{g} / \mathrm{kg}$ ) or PBS $/ 0.025 \%$ BSA (control group) for $7 \mathrm{~d}$. Litters were given several forms of therapy, and were inoculated with GBS (1 $\times 10^{8}$ organisms $/ \mathrm{kg}$ ) s.c. on $\mathrm{d} 8$. Treatment modalities included the following: 1) $7 \mathrm{~d} \mathrm{rmGM}-\mathrm{CSF}$ i.p. $75 \mu \mathrm{g} / \mathrm{kg} / \mathrm{d}$; 2) $7 \mathrm{~d}$ of PBS/ 
$0.025 \% \mathrm{BSA}$; 3) $7 \mathrm{~d}$ rmGM-CSF and antibiotics, ampicillin (Bristol Laboratories, Evansville, IN) $(150 \mathrm{mg} / \mathrm{kg} / \mathrm{d})$, and gentamicin (Elkins-Sinn, Cherry Hill, NJ) $(6.5 \mathrm{mg} / \mathrm{kg} / \mathrm{d})$ intramuscularly divided and administered twice a day, started $24 \mathrm{~h}$ after GBS; and 4) $7 \mathrm{~d}$ PBS $/ 0.025 \%$ BSA and the same antibiotic therapy. Mortality and morbidity were monitored throughout the sepsis study.

Statistical analysis. All results are expressed as mean values plus or minus SEM of $8-15$ animals, or three to five replicates of blood, bone marrow, or liver/spleen samples. The probability of significant differences when comparing two treated groups was determined with the use of the unpaired $t$ test, and the probability of significant differences when examining multiple treatments was determined by using the analysis of variance followed by the Student-Newman-Keuls multiple range tests to define the unique subsets within the study. Statistical analyses were performed using the Biostat I statistical program (Sigma Soft, Placentia, CA) for the IBM personal computer. $p$ values $<0.05$ are considered significant.

\section{RESULTS}

The absolute neutrophil count, i.e. peripheral neutrophilia, was determined on d 1, 3, and 7 after i.p. rmGM-CSF and i.p. rmIL-3 administration. A dose of $10 \mu \mathrm{g} / \mathrm{kg}$ of i.p. rmIL-3 was chosen after studying the dose response of rmIL-3 $(0.1,1.0$, and $10.0 \mu \mathrm{g} / \mathrm{kg}$ ). Day 7 absolute neutrophil count: $0.1,541 \pm 70$ $\mathrm{mm}^{3} ; 1.0,540 \pm 144 \mathrm{~mm}^{3}$, and $10.0,896 \pm 148 \mathrm{~mm}^{3}(0.1$ and 1.0 versus $10.0, p<0.04)$. Day 8 bone marrow CFU-GM: 0.1 , $47 \pm 2.9$ versus $1.0,46 \pm 2.2$ versus $10.0,68 \pm 2.2 ; 0.1$ and 1.0 versus $10.0, p<0.02$. Within the first day of administration, there were no significant differences between rmGM-CSF and rmIL-3 compared with controls. However, on d 3 and additionally after $7 \mathrm{~d}$ of administration, there was a significant difference in the peripheral neutrophil count after i.p. rmGMCSF compared with control treated animals. There was no significant difference, however, after i.p. rmIL-3 administration (Fig. 1). On $\mathrm{d} 7$, the absolute neutrophil count $\left(\mathrm{mm}^{3}\right)$ after $7 \mathrm{~d}$ of i.p. rmGM-CSF was $2218 \pm 54$ versus $1288 \pm 169(p<0.001)$. Comparatively, $7 \mathrm{~d}$ of i.p. rmIL-3 did not induce a significant increase in peripheral neutrophilia: $d 7,789 \pm 193$ versus $642 \pm$ $282 \mathrm{~mm}^{3} ; p=\mathrm{NS}$, rmIL-3 versus PBS/BSA. Additionally, rmIL3 failed to induce any significant changes in the peripheral basophil or eosinophil count and did not result in any change in the peripheral platelet count: $\mathrm{d} 7,791 \pm 95$ versus $884 \pm 74 \times$ $10^{3} / \mathrm{mm}^{3} ; p=\mathrm{NS}, \mathrm{rmIL}-3$ versus PBS/BSA.

The bone marrow NSP was determined on d 8 after 7 consec-

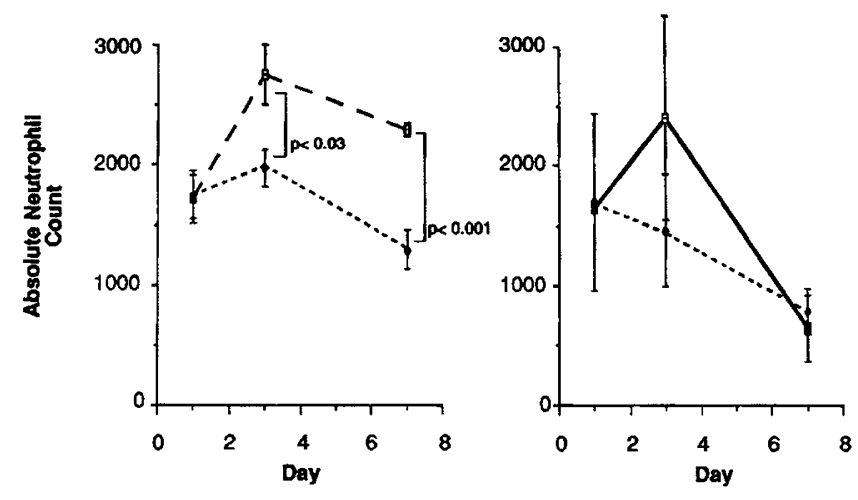

Fig. 1. Neonatal Sprague Dawley rats ( $\leq 24 \mathrm{~h}$ old) received rmGMCSF, rmIL-3, or $0.025 \%$ PBS/BSA by i.p. injection daily for $7 \mathrm{~d}$. Blood samples were obtained by nicking the jugular vein with a sterile needle and collecting $10 \mu \mathrm{L}$ of free-flowing blood. Samples were electronically counted, and a 100-200 cell differential was performed on Wright-stained blood smears. Values reflect the mean absolute neutrophil count $\left(\mathrm{mm}^{3}\right)$ \pm SEM of 20 animals at each time point. rmGM-CSF (- - ), rmIL3 (_- $)$, PBS $/ 0.25 \%$ BSA (--.). utive days of either i.p. rmGM-CSF or i.p. rmIL-3. rmGM-CSF induced a significant increase in the bone marrow NSP $(50 \%)(p$ $<0.025$ ) (Table 1). rmIL-3, however, a more early-acting hematopoietic growth factor, failed to induce a significant increase in the bone marrow NSP (Table 1). The bone marrow NPP was also calculated after $7 \mathrm{~d}$ administration of i.p. rmGM-CSF and rmIL-3. There was, however, no significant difference in the bone marrow NPP by either hematopoietic colony stimulating factor (Table 2).

The bone marrow committed myeloid stem cell pool (CFUGM) was additionally determined on $\mathrm{d} 8$ after 7 consecutive days of both i.p. rmGM-CSF and i.p. rmIL-3. Although i.p. rmGMCSF failed to induce a significant increase in myeloid progenitor stem cell colony formation, rmIL-3 induced a mild but significant increase $(15 \%) p<0.001)$ in myeloid CFU-GM colony formation (Table 1).

Combined liver and spleen NSP, NPP, myeloid CFU-GM colony formation, and CFU-GM proliferative rates were additionally assessed after $7 \mathrm{~d}$ administration of both i.p. rmGMCSF and i.p. rmIL-3. There was, however, no significant increase by either i.p. CSF on combined liver/spleen NSP, NPP, CFUGM colony formation, or CFU-GM proliferative rate (Table 2).

Eight-d-old newborn rats were inoculated with GBS, and the mortality rate after $7 \mathrm{~d}$ of i.p. rmGM-CSF or PBS/BSA was evaluated. Four groups of animals were compared in this part of the study. The first group of animals received $7 \mathrm{~d}$ of PBS/BSA and were then inoculated with GBS. The second group of animals received $7 \mathrm{~d}$ of i.p. rmGM-CSF and were then subsequently inoculated with GBS. The third group of animals received the identical PBS/BSA as in group 1 and GBS inoculation on $\mathrm{d} 8$, and then subsequently were given ampicillin and gentamicin 24 $\mathrm{h}$ after GBS inoculation. The last group of animals received $7 \mathrm{~d}$ of rmGM-CSF inoculated with GBS on $d 8$ and received ampicillin plus gentamicin $24 \mathrm{~h}$ after GBS inoculation. Although the group of animals pretreated with $7 \mathrm{~d}$ of rmGM-CSF had a mild increase in the peripheral neutrophil count and bone marrow NSP, there was no reduction in the mortality rate with or without antibiotic administration $(90 \mathrm{~h})(\mathrm{rmGM}-\mathrm{CSF}+$ antibiotic versus $\mathrm{PBS} / \mathrm{BSA}+$ antibiotic, 57 versus $59 \%$ survival rate; $p=\mathrm{NS}$ ) (Fig. 2).

\section{DISCUSSION}

Although the high mortality rate associated with bacterial sepsis during the newborn period appears to be multifactorial, one of the most important deficits of the neonatal immune system contributing to this high incidence is the quantitative deficiency of the myeloid and phagocytic system (1). Future preventive and/or concurrent therapy of neonatal sepsis, therefore, may require the use of adjuvant immunologic therapy. Newborn rats have significantly reduced myeloid progenitor pools (CFU-GM) (20\%), and require $4 \mathrm{wk}$ of developmental maturation to attain normal adult levels. Additionally, newborn rats have markedly reduced bone marrow NSP (25\%), and also require 4-6 wk to mature to normal adult levels. We therefore have begun to investigate new pharmacologic and biologic methods to modulate newborn myeloid proliferation and differentiation (22-25). Diminished newborn myeloid progenitor cells (CFU-GM), near maximal proliferative capacity of myeloid progenitor cells, and an accelerated release of NSP cells from the newborn bone marrow reserve predispose the newborn to depletion of bone marrow mature neutrophil reserves and the subsequent development of significant peripheral neutropenia during overwhelming bacterial sepsis $(2,4,26)$.

Recently, GM-CSF has been demonstrated to enhance myelopoiesis after bone marrow transplantation and has been used as adjuvant therapy in adults receiving intensive chemotherapy and, additionally, as specific immunomodulating therapy in patients with aplastic anemia, myelodysplasic syndromes, and AIDS (9). GM-CSF has been demonstrated to enhance hemato- 
Table 1. Effect of 7 d of i.p. rmGM-CSF or rmIL-3 on newborn rat bone marrow NSP and colony formation*

\begin{tabular}{lcccc}
\hline & rmGM-CSF & PBS/BSA & rmIL-3 & PBS/BSA \\
\hline Bone marrow NSP $\left(\mathrm{mm}^{3}\right)$ & $3427 \pm 238 \dagger$ & $2280 \pm 165$ & $6964 \pm 730$ & $5201 \pm 334$ \\
Bone marrow CFU-GM colonies & $95 \pm 9$ & $92 \pm 7$ & $123 \pm 3 \dagger$ & $107 \pm 4$ \\
\hline
\end{tabular}

${ }^{*}$ rmGM-CSF, rmIL-3, or $0.025 \%$ BSA/PBS was administered to neonatal rats ( $\leq 24 \mathrm{~h}$ old) by i.p. injection for $7 \mathrm{~d}$. Bone marrow NSP was determined by the aseptic removal of the femurs and the flushing of the bone marrow into a known quantity of Hanks' balanced salt solution. Electronic cell counts were performed, and a 500-cell differential was obtained on Wright-stained cytospin preparations. Cells for colony assays were suspended in $1.1 \%$ methyl/cellulose $\alpha$-media, and triplicate cultures were plated at $2.0 \times 10^{5}$ cells per plate. Colonies were evaluated at d 14 by scoring the aggregates and plucking colonies at random for differential staining. Data reflects the mean value \pm SEM of two experiments done in triplicate in which 12 animals per treated litter were analyzed.

+ Significance of $p<0.05$.

Table 2. Effect of $7 d$ of i.p. rmGM-CSF or rmIL-3 on newborn rat bone marrow and liver/spleen myelopoiesis*

\begin{tabular}{lcccc}
\hline & rmGM-CSF & PBS/BSA & rmlL-3 & PBS/BSA \\
\hline Bone marrow NPP $\left(\mathrm{mm}^{3}\right)$ & $2393 \pm 88$ & $2336 \pm 240$ & $3014 \pm 625$ & $3641 \pm 440$ \\
Bone marrow CFU-GM proliferative rate (\%) & $57.7 \pm 6.1$ & $52.1 \pm 9.1$ & $73.2 \pm 2.5$ & $69.5 \pm 5$ \\
Liver/spleen NSP $\left(\mathrm{mm}^{3}\right)$ & $16402 \pm 5886$ & $13218 \pm 1105$ & $20083 \pm 5765$ & $23785 \pm 4519$ \\
Liver/spleen NPP $\left(\mathrm{mm}^{3}\right)$ & $21748 \pm 2264$ & $23298 \pm 50$ & $36033 \pm 17572$ & $23115 \pm 1641$ \\
Liver/spleen CFU-GM colonies & $19 \pm 9$ & $18 \pm 9$ & $15 \pm 11$ & $13 \pm 9$ \\
Liver/spleen CFU-GM proliferative rate (\%) & $35.6 \pm 9.0$ & $39.6 \pm 15$ & $30.2 \pm 9.2$ & $39.6 \pm 15$ \\
\hline
\end{tabular}

${ }^{*}$ rmGM-CSF, rmIL-3, or $0.025 \%$ BSA/PBS was administered to neonatal rats by i.p. injection daily for $7 \mathrm{~d}$. Bone marrow cells were recovered after the aseptic removal of the femurs and flushing the bone marrow into a known quantity of balanced saline. Liver/spleen cells were isolated from the organs, which were aseptically removed and finely minced in a known quantity of saline. Bone marrow and liver/spleen NPP and NSP were determined by performing electronic cell counts, and a 500-cell differential was obtained on the Wright-stained cytospin preparations. Bone marrow and liver/spleen CFU-GM proliferative rates were evaluated by the thymidine suicide method. Bone marrow and liver/spleen CFU-GM were determined by suspending isolated cells in $1.1 \%$ methylcellulose/ $\alpha$-media and plating $2.0 \times 10^{\mathrm{s}}$ cells in triplicate. Colonies were evaluated at $\mathrm{d}$ 14 by scoring the aggregates and plucking colonies at random for differential staining. Values represent the mean value \pm SEM of two experiments done in triplicate in which 12 animals per treated litter were analyzed.

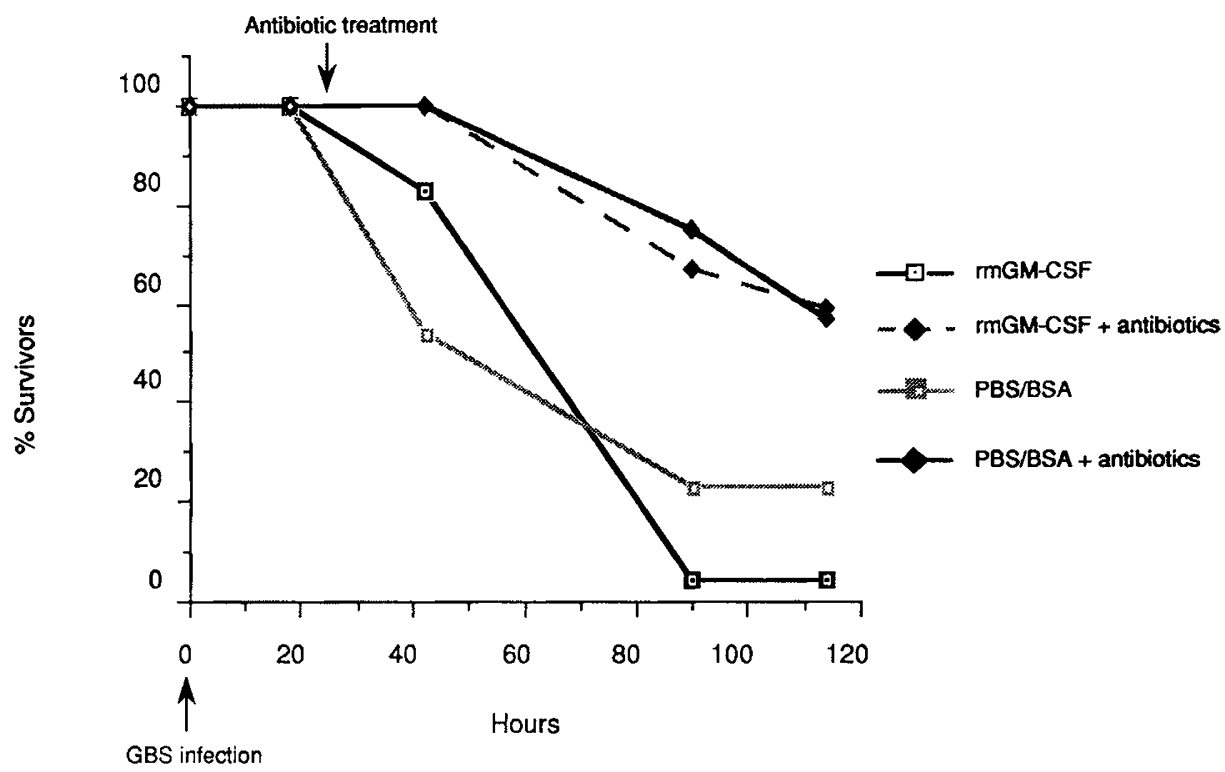

Fig. 2. Litters of neonatal rats ( $\leq 24 \mathrm{~h}$ old) received $\mathrm{rmGM}-\mathrm{CSF}$ or $0.025 \% \mathrm{BSA} / \mathrm{PBS}$ i.p. for $7 \mathrm{~d}$. Litters were inoculated with $1 \times 10^{8} \mathrm{GBS} / \mathrm{g}$ on $\mathrm{d} 8$, and $24 \mathrm{~h}$ later, groups received antibiotics (ampicillin, $150 \mathrm{mg} / \mathrm{kg} / \mathrm{d}$, and gentamicin, $6.5 \mathrm{mg} / \mathrm{kg} / \mathrm{d}$ ) every $12 \mathrm{~h}$ or no additional treatment. The graph represents the percent survival after $96 \mathrm{~h}$.

poiesis and host defense by inducing peripheral neutrophilia secondary to egress of NSP cells within the first $24 \mathrm{~h}$ of administration, to stimulate sustained peripheral neutrophilia by inducement of early myeloid progenitor cells to undergo proliferation and differentiation, and, lastly, to correct in vitro mature effector neutrophil physiologic dysfunction (27-29). Human IL3 , however, has only recently begun to undergo investigation in human clinical trials, and is just entering phase I and phase II trials in patients with bone marrow failure (30). Additionally, human IL-3, when administered to nonhuman primates, has been demonstrated to possess synergistic activity with GM-CSF in stimulating hematopoiesis and the induction of increased circulating levels of eosinophils, monocytes, and neutrophils (31). Previous primate studies have suggested that the hematologic effect of IL-3 alone of inducing peripheral neutrophilia is markedly reduced compared with the leukocytosis observed after either GM-CSF or G-CSF.

In our present study, we investigated the effects of both rmGMCSF and rmIL-3 on neonatal myelopoiesis. Our study has suggested that rmGM-CSF, a more lineage-specific, class 1 hematopoietic CSF, induced more peripheral neutrophilia and a $50 \%$ increase in the bone marrow NSP, but had little effect on myeloid CFU-GM colony formation, proliferative rate, and bone marrow proliferative pool. In contrast, rmIL-3, an earlier and less lineage- 
specific multicolony stimulating factor, failed to induce any peripheral neutrophilia and had no effect on bone marrow NSP, NPP, or bone marrow CFU-GM proliferative rate. rmIL-3, however, appeared to mildly increase bone marrow CFU-GM colony formation. Neither rmGM-CSF nor rmIL-3 had any significant effect on the combined liver/spleen NSP, NPP, CFU-GM colony formation, or CFU-GM proliferative rate.

Previous studies by Erdman et al. (4) demonstrated that 1-wkold neonatal rats possessed only $50 \%$ of normal bone marrow storage pools compared with developmentally normal adult rats. In our present study, $7 \mathrm{~d}$ of administration of rmGM-CSF to newborn rats appeared to increase the 1-wk-old NSP by $50 \%$. This $50 \%$ increase in the NSP approximates the normal values attained in normal adult rat bone marrow NSP. In comparison, in our previous studies using $7 \mathrm{~d}$ of rhG-CSF, a more myeloid lineage-specific hematopoietic CSF, we demonstrated a $100 \%$ increase in the 1-wk-old newborn rat NSP (21).

Seven $\mathrm{d}$ of $\mathrm{rmGM}$-CSF also induced a significant increase in the $\mathrm{d} 7$ peripheral neutrophil count $(75 \%, p<0.001)$. However, this increase in the 7 peripheral neutrophil count was somewhat weaker compared with our previous 7-d studies with rhG-CSF, which resulted in an increase in the $\mathrm{d} 7$ peripheral neutrophil count of almost $750 \%(20,21)$. rhIL-3, however, did not induce any increase in the peripheral neutrophil count during the entire $7 \mathrm{~d}$ of administration. Our findings are consistent with previous (7-d rhIL-3) studies of primates, which also failed to demonstrate an increase in the peripheral neutrophil count (31-33).

We additionally assessed the effect of $7 \mathrm{~d}$ of i.p. rmGM-CSF or i.p. rmIL-3 on d 8 bone marrow CFU-GM colony formation. Although rmGM-CSF had a mild, but not statistically significant increase in bone marrow CFU-GM colony formation, rmIL-3, an earlier-acting hematopoietic CSF, induced a significant increase in bone marrow CFU-GM colony formation. Both rmGM-CSF and rmIL-3 also appeared to mildly increase the bone marrow CFU-GM proliferative rate. Neither rmGM-CSF nor rmIL-3 resulted, however, in an increase in the bone marrow NPP or in the myeloid proliferative or storage pools of the combined liver/spleen homogenates. Our findings in the present newborn rat study are similar to findings of Pojda et al. (34), who studied the hematologic effects of daily rmGM-CSF in normal adult BDF mice for a period of $11 \mathrm{wk}$. Specifically, after daily injections of rmGM-CSF for $1 \mathrm{wk}$, they found no increase in bone marrow CFU-GM or colony forming unit of mixed erythroid and granulocyte-monocyte colonies formation (34). Additionally, this latter study also failed to demonstrate an increase in spleen CFU-GM progenitor proliferation after $7 \mathrm{~d}$ of rmGM-CSF in adult mice (34). Metcalf et al. (35) additionally studied the hematologic effects of $6 \mathrm{~d}$ of i.p. rmGM-CSF administered to adult BALB/c mice. This study, similar to ours, also demonstrated an increase in the 7-d peripheral neutrophil count but, in contrast to our study, showed a mild decrease in CFUGM after 6 d of i.p. rmGM-CSF.

Because $7 \mathrm{~d}$ of rmGM-CSF induced a mild increase in peripheral neutrophil count and an increase in the bone marrow NSP, we additionally investigated whether this effect would modulate the mortality associated with GBS infection. Seven d of rmGMCSF administration, however, failed to synergistically enhance survival after GBS experimental infection in antibiotic-treated newborn animals. Both groups of animals receiving PBS/BSA or rmGM-CSF plus antibiotics had a $57-59 \%$ survival rate after GBS inoculation. This, however, contrasts with our previous studies with $7 \mathrm{~d}$ rhG-CSF, which demonstrated an almost $100 \%$ increase in survival over PBS/BSA plus antibiotic-treated animals $(20,21)$. In the rhG-CSF study, however, $7 \mathrm{~d}$ of this class II lineage-specific myeloid growth factor induced an almost $750 \%$ increase in the peripheral neutrophil count, and an almost $100 \%$ increase in the bone marrow NSP. In our present study, rmGMCSF only induced a $75 \%$ increase in peripheral neutrophil count, and only a $50 \%$ increase in the bone marrow NSP. A comparison of these two studies suggests that prophylactic CSF administra- tion requires a very significant increase in the peripheral neutrophil count and bone marrow NSP to prevent significant peripheral neutropenia and bone marrow NSP depletion during experimental sepsis.

It appears that IL-3 alone has minimal effects on the inducement of peripheral neutrophilia, bone marrow, and liver/spleen storage pools. IL-3 has previously been demonstrated to be more effective than GM-CSF in supporting colony formation of very early primitive multipotential blast cells (36). IL-3 supports several divisions of early progenitor cells, but the resulting proliferation of stem cells may rapidly regress in the absence of a second, more lineage-specific growth factor (37). IL-3, in fact, appears to act synergistically with a number of hematopoietic CSF to induce various colony formations: with IL-6 to support early blast cell colony formation, with G-CSF to support granulocytic colony formation, and with GM-CSF to support granulocyte, eosinophil, and monocyte colony formation $(38,39)$.

In summary, we have demonstrated that $7 \mathrm{~d}$ of administration of i.p. rmGM-CSF in newborn rats induces significant changes in the peripheral neutrophil count and the bone marrow NSP compared with a similar course of rmIL-3. This increase in the peripheral neutrophil count and bone marrow NSP, however, failed to be prophylactic against experimental GBS infection. Seven $\mathrm{d}$ of rmIL-3 failed to induce significant changes in the peripheral neutrophil count and/or the bone marrow and liver/ spleen NSP. rmIL-3, however, significantly increased bone marrow CFU-GM colony formation. rmIL-3 appears to expand newborn myeloid progenitor cells, but may require the sequential addition of a later acting, lineage-specific CSF such as G-CSF or GM-CSF to optimize its induction of bone marrow myelopoiesis and inducement of peripheral neutrophilia. Optimal stimulation of neonatal hematopoiesis may require the combination of both early- and late-acting hematopoietic CSF. Enhancement of neonatal host defense may require the developmental maturation of myelopoiesis and functional activation of mature effector phagocytic circulating immune cells. Future studies are underway to develop the optimal regimen for enhancing neonatal myelopoiesis and host defense.

Acknowledgment. The authors thank Nancy Franks for her expert editorial assistance in the preparation of this manuscript.

\section{REFERENCES}

1. Cairo MS 1989 Neonatal neutrophil host defense. Am J Dis Child 143:40-46

2. Christensen RD, Rothstein G 1984 Pre- and postnatal development of granulocyte stem cells (CFUc) in the rat. Pediatr Res 18:599-602

3. Christensen RD, Harper TE, Rothstein G 1986 Granulocyte-macrophage progenitor cell (CFU-GM) in term and preterm neonates. $J$ Pediatr 109:1047-1051

4. Erdman SH, Christensen RD, Bradley PP, Rothstein G 1982 Supply and release of storage neutrophils: a developmental study. Biol Neonate 41:132137

5. Christensen RD, Macfarlane JL, Taylor NL, Hill HR, Rothstein G 1982 Blood and marrow neutrophils during experimental group B streptococcal infection: quantification of the stem cell, proliferative, storage and circulating pools. Pediatr Res 16:549--553

6. Cannistra SA, Griffin JD 1988 Regulation of the production and function of granulocytes and monocytes. Semin Hematol 25:173-188

7. Clark SC, Kamen R 1987 The human hematopoietic colony-stimulating factors. Science 236:1229-1237

8. Sieff CA 1987 Hematopoietic growth factors. J Clin Invest 79:1549-1557

9. Groopman JE, Molina JM, Scadden DT 1989 Hematopoietic growth factors biology and clinical applications. N Engl J Med 321:1449-1459

10. Yang YC, Clark SC 1989 Interleukin-3: molecular biology and biologic activities. Hematol Oncol Clin North Am 3(3):441-452

11. Yang YC, Ciarletta AB, Temple PA, Chung MP, Kovacic S, Witek-Giannotti JS, Leary AC, Kriz R, Donahue RE, Wong GG 1986 Human IL-3 (multiCSF): identification by expression cloning of a novel hematopoietic growth factor related to murine IL-3. Cell 47:3-10

12. Le Beau MM, Epstein ND, O'Brien SJ, Nienhuis AW, Yang YC, Clark SC, Rowley JD 1987 The interleukin 3 gene is located on human chromosome 5 and is deleted in myeloid leukemias with a deletion of $5 q$. Proc Natl Acad Sci USA 84:5913-5917

13. Fung MC, Hapel AJ, Ymer S, Cohen DR, Johnson RM, Campbell HD, Young ID 1984 Molecular cloning of cDNA for murine interleukin-3. Nature 307:233-237 
14. Lopez AF, To LB, Yang YC, Gamble JR, Shannon MF, Burns GF, Dyson PG, Juttner CA, Clark S, Vadas MA 1987 Stimulation of proliferation, differentiation, and function of human cells by primate interleukin 3. Proc Natl Acad Sci USA 84:2761-2765

15. Sieff CA, Niemeyer CM, Nathan DG, Edern SC, Biever FR, Yang YC, Wong $\mathrm{G}$, Clark SC 1987 Stimulation of human hematopoietic colony formation by recombinant gibbon multi-colony stimulating factor or interleukin-3. J Clin Invest 80:818-815

16. Wong G, Witek JS, Temple PA, Wilkens KM, Leary AC, Luxemburg DP Jones SS, Brown EL, Kay RM, Orr EC, Shoemaker C, Golde DW, Kaufman RJ, Hewick RM, Want EA, Clark SC 1985 Human GM-CSF:molecular cloning of the complementary DNA and purification of the natural and recombinant proteins. Science 228:810-1173

17. Sieff CA, Emerson SG, Donahue RE, Nathan DG, Wang Ea, Wong EG, Clark SC 1985 Human recombinant granulocyte macrophage colony stimulating factor: A multilineage hematopoietin. Science 230:1171-1173

18. Cairo MS, van de Ven CJ, Toy C, Mauss D, Sender L 1989 Recombinant human granulocyte-macrophage colony stimulating factor primes neonatal granulocytes for enhanced oxidative metabolism and chemotaxis. Pediatr Res 26:395-399

19. Cairo MS 1989 Review of G-CSF and GM-CSF effects on neonatal neutrophil kinetics. Am J Pediatr Hematol Oncol 11(2):238-244

20. Cairo MS, Mauss D, Kommareddy S, Norris K, van de Ven C, Modanlou H 1990 Prophylactic or simultaneous administration of rhG-CSF in the treatment of group B streptococcal sepsis in neonatal rats. Pediatr Res 27:612616

21. Cairo MS, Mauss D, van de Ven C 1990 Seven day administration of rhGCSF to newborn rats: modulation of neonatal neutrophilia, myelopoiesis and group B streptococcus sepsis. Blood 76:1788-1794

22. Cairo MS 1991 Cytokines: a new immunotherapy. Clinics in Perinatology (in press)

23. Akenzua GI, Hui YT, Milner R, Zipursky A 1974 Neutrophil and band counts in the diagnosis of neonatal infection. Pediatrics 54:38-42

24. Zipursky A, Palko J, Milner R, Akenzua GI 1974 The hematology of bacterial infections in premature infants. Pediatrics 57:889-893

25. Manroe BL, Rosenfeld CR, Weinberg AG, Browne R 1977 The differential leukocyte count in the assessment and outcome of early-onset neonatal group B streptococcal disease. J Pediatr 91:632-637

26. Manroe BL, Weinberg AG, Rosenfeld CR, Browne R 1979 The neonatal blood count in health and disease. I. Reference values for neutrophilic cells. J Pediatr 95:89-98

27. Nienhuis AW, Donahue RE, Karlsson S, Clark SC, Agricola B, Antinoff N Pierce JE, Turner P, Anderson WF, Nathan DG 1987 Recombinant human granulocyte-macrophage colony-stimulating factor (GM-CSF) shortens the period of neutropenia after autologous bone marrow transplantation in a primate model. J Clin Invest 80:573-577

28. Groopman JE, Mitsuyasu RH, DeLeo MJ, Oette DH, Golde DW 1987 Effect of recombinant human granulocyte-macrophage colony-stimulating factor on myelopoiesis in the acquired immunodeficiency syndrome. N Engl J Med 317:593-598

29. Baldwin GC, Gasson JC, Quan SG, Fleischmann J, Weisbart R, Oette D, Mitsuyasu RT, Golde DW 1988 Granulocyte-macrophage colony-stimulating factor enhances function in acquired immunodeficiency syndrome patients. Proc Natl Acad Sci USA 85:2763-2766

30. Gruber A, Kelly AB, Harker LA, Hanson SR, Griffin JH 1989 Inhibition of thrombus formation by infusion of activated protein $\mathrm{C}$ with urokinase in a primate thrombosis model. Blood 74(suppl 1):50A(abstr)

31. Donahue RE, Sechra J, Metzger M, Lefebvre D, Rock B, Carbone S, Nathan DG, Garnick M, Sehgal PK, Laston D 1988 Human IL-3 and GM-CSF act synergistically in stimulating hematopoiesis in primates. Science 241:18201823

32. Yang YC, Clark SC 1989 Interleukin-3: molecular biology and biologic activities. Hematol Oncol Clin North Am 3(3):441-452

33. Mayer $P$, Valent $P$, Schmidt $G$, Liehl E, Bettelheim P 1989 The in vivo effects of recombinant human interleukin-3: demonstration of basophil differentiation factor, histamine-producing activity, and priming of GM-CSF-responsive progenitors in non-human primates. Blood 74:613-618

34. Pojda Z, Molineux G, Dexter TM 1989 Effects of long term in vivo treatment of mice with purified murine recombinant GM-CSF. Exp Hematol 17:11001104

35. Metcalf D, Begley CG, Williamson DJ, Nice EC, De Lamarter J, Mermod J, Thatcher D, Schmidt A 1987 Hematopoietic responses in mice injected with purified recombinant murine GM-CSF. Exp Hematol 15:1-9

36. Leary AG, Ikebuchi K, Hirai Y, Wong GG, Yang YC, Clark SC, Ogawa M 1988 Synergism between interleukin- 6 and interleukin-3 in supporting proliferation of human hematopoietic stem cells: comparison with interleukin1 $\alpha$. Blood 71:1759-1763

37. Sonada Y, Yang YC, Wong GG, Clark SC, Ogawa M 1988 Analysis in serumfree culture of the targets of recombinant human hemopoietic growth factors: interleukin 3 and granulocyte/macrophage-colony stimulating factor are specific for early development stages. Proc Natl Acad Sci USA 85:43604364

38. Ikebuchi K, Wong GG, Clark SC, Ihle JN, Hirai Y, Ogawa M 1987 Interleukin 6 enhancement of interleukin 3-dependent proliferation of multipotential hemapoietic progenitors. Proc Natl Acad Sci USA 84:9035-9039

39. Paquette RL, Zhou JY, Yang YC, Clark SC, Koeffler P 1988 Recombinant gibbon interleukin-3 acts synergistically with recombinant human G-CSF and GM-CSF in vitro. Blood 71:1596-1600 